CORIGINAL ARTICLE

Volume 15 Issue 12020

DOI: 10.21315/aos2020.15.1.426

ARTICLE INFO

Submitted: $16 / 01 / 2020$

Accepted: 09/06/2020

Online: $15 / 07 / 2020$

\section{Malaysian Dental Practitioner Personal Experience and Barriers to Attend Continuing Professional Development (CPD) Programme}

\author{
Nor Faharina Abdul Hamida ${ }^{\text {, }}$ Izyan Hazwani Baharuddin ${ }^{b}$ \\ ${ }^{a}$ Centre of Restorative Studies, Faculty of Dentistry, Universiti Teknologi \\ MARA, Sungai Buloh Campus, 47000 Sungai Buloh, Selangor, \\ Malaysia \\ ${ }^{b}$ Faculty of Dentistry, Universiti Teknologi MARA, Sungai Buloh \\ Campus, 47000 Sungai Buloh, Selangor, Malaysia
}

"Corresponding author: faharina83@gmail.com

How to cite this article: Abdul Hamid NF, Baharuddin IH (2020). Malaysian dental practitioner personal experience and barriers to attend continuing professional development (CPD) programme. Arch Orofac Sci, 15(1): 45-54. https://doi.org/10.21315/aos2020.15.1.426

To link to this article: https://doi.org/10.21315/aos2020.15.1.426

\begin{abstract}
The significance of continuing professional development (CPD) among dental practitioners (DPs) is well-recognised by the Malaysian Dental Council (MDC). CPD has become mandatory to all DPs prior to renewal of annual practising certificate (APC) following the enforcement of Dental Act 2018. This study aimed to determine the personal experience of Malaysian DPs in CPD programmes and to identify the barriers to attend CPD activities. This was a cross-sectional study of which a paperbased, self-administered questionnaire (pre-test, content validated) was administered to all participants ( $\mathrm{n}=229$, response rate $=49.7 \%$ ) who participated in CPD programmes organised by the Faculty of Dentistry, Universiti Teknologi MARA (UiTM) from April 2017 until November 2017. Almost all respondents $(92.1 \%)$ acknowledged the importance of undertaking CPD. Some of them $(68.9 \%)$ agreed that the employer provides adequate support to carry out the CPD activities. Majority of the respondents $(62.3 \%)$ participated in $1-4$ hours of CPD on average per month and most of them (42.1\%) attended 5-10 days CPD course in the year 2017. Barriers to CPD participation were current workload, lack of time and lack of financial support. Malaysian DPs are currently engaging in CPD programmes and considered the compulsory CPD to be beneficial to them as professionals even before the compulsory implementation in 2018. This study provides valuable information to assist Malaysian CPD providers in formulating appropriate approaches while planning the CPD courses and as well as to identify the potential barriers in attending the CPD programmes.
\end{abstract}

Keywords: Barrier; continuing professional development; dental practitioner; dentistry; Malaysia

\section{INTRODUCTION}

The Dental Act 2018 (Act 804) was published in the Malaysian Federal Gazette on 26 June 2018 after being passed in the Parliament and granted the Royal Assent (Dental Act, 2018). With the implementation of the Dental Act 2018; the Dental Act 1971 was repealed after effectively regulated Malaysian dental practice for the past 49 years (Dental Act, 2018). The Dental Act 2018 has profound implications on the dental practice; mostly on the registration of dental therapists in 
the private sector, mandatory continuing professional development (CPD) and professional insurance cover for renewal of the annual practising certificate (APC) and enforcement capabilities (Dental Act, 2018).

The Malaysian regulatory body, MDC, has highlighted the importance of CPD to maintain and broaden the knowledge and skills as well as to develop the professional and personal qualities required in their professional lives (MDC, 2018). CPD plays an important role in educating the dental practitioners (DPs) to improve patient outcomes as it is not only concerned with the updating clinical and scientific knowledge but also maintaining expertise across the whole range of activities (Ikenwilo and Skåtun, 2014; MDC, 2018).

The Dental Act 2018 states that "to practise dentistry in Malaysia, dental practitioners have to be registered with the MDC and hold a current annual practising certificate (APC)" (Dental Act, 2018; MDC, 2019). Renewal of APC or Temporary Practicing Certificate (TPC) must be submitted to MDC via online or manually before $1 \mathrm{st}$ of November of the current year. All DPs must produce evidence of sufficient CPD points, evidence of Professional Indemnity Cover, evidence of approval or registration under the Private Healthcare Facilities and Services Act 1998 (PHFSA) for all private healthcare facilities, a fee of RM100 for each private healthcare facility together with the application for APC or TPC renewal (Dental Act, 2018; MDC, 2019). This rule involves all DPs who practise in Malaysia including those who work on a contract basis in the public and private sectors, lecturers in institutions of higher education or DPs who visit Malaysia for short hands-on courses (MDC, 2018).

Within the new revalidation structure preceding renewal of APC or TPC, CPD becomes the main component to support the information to validate the practising licence. Thus, the aim of this study was to assess the personal experience of Malaysia DPs in CPD programmes, to assess the time spent on CPD training and the perceived barriers in attending CPD course in Malaysia. The finding of this study is anticipated to help the CPD organiser in identifying and dealing with the potential barriers that may impact on participation and engagement on CPD programme in future.

\section{MATERIALS AND METHODS}

\section{Study Design and Participants}

This was a cross-sectional study. All 229 DPs that had attended the CPD programmes organised at University Teknologi MARA (UiTM) from April 2017 until November 2017 were invited to participate in the survey. The study was approved prior to its commencement by the UiTM Human Ethics Advisory Committee (Ref. No.: 600-IRMI $5 / 1 / 6)$.

\section{Measurement Tools}

A self-administered paper-based questionnaire was developed based on an existing validated study instrument (Sturrock and Lennie, 2009). The questions were modified to suit the local conditions prior to the main survey. The modified questionnaire was sent to an expert for content validation where modifications were made accordingly. Then, face validity was performed among five dental officers to assess the suitability, understanding and sequencing of questions. Modifications to the final version of the questionnaire were made according to their feedback. The aim of the survey was to collect information on four areas which were: (1) The respondents' personal and professional background; (2) Respondent's preference on learning modality and time spent on training; (3) DP's personal experience in CPD; and (4) Barrier to participate in CPD programme. Section 1 mainly focused on the respondents' personal and professional background which include sociodemographic characteristics, place of employment and location of practise. Section 2 involved six questions regarding the CPD 
preferences on learning modality among DPs and two questions regarding participation on CPD in year 2017. Six items regarding personal experience about CPD were asked in Section 3 utilising the Likert-type response to statements (on a numerical scale anchored at 1-strongly disagree and 5-strongly agree and 3-neutral point). Section 4 examined the barrier of DPs to participate in CPD and factors that influencing the respondents in choosing the CPD programme. There was one open-ended question at the end of the section to collect additional information regarding the CPD.

\section{Sample Size Determination}

The calculation of the sample size was determined by Epi Info Software ${ }^{\mathrm{TM}}$ version 7.2.3.1 (Atlanta, Georgia), with population set at $229, \alpha=0.05$ and $95 \%$ confidence interval and the minimum sample size required was 143 respondents.

\section{Data Collection}

A paper-based questionnaire was distributed to all participants during registration of each CPD course. The housekeeping announcement was made in between the lectures in order to improve the response rate. The collection box was placed at registration counter for the respondent to return the completed questionnaire. All responses were anonymous. Those who returned the answered questionnaire were all included in this study. However, incomplete questionnaire with more than $30 \%$ unanswered questions were excluded from analysis.

\section{Statistical Analysis}

The data were analysed using the Statistical Package for Social Sciences (SPSS) software programme version 23 (IBM SPSS Statistics for Windows, Version 23.0. Armonk, NY: IBM Corp) for descriptive analysis and Fisher's Exact Test. Reliability by internal consistency of the questions was check by Cronbach's alpha.

\section{RESULTS}

\section{Reliability by Internal Consistency}

Cronbach's alpha obtained was 0.7, suggesting a good internal consistency among the questions asked, which also reflects a good reliability of the questions.

\section{The Respondents' Personal and Professional Background}

All 229 DPs that attended CPD programme from April 2017 until November 2017 were invited to participate in this survey. Only $(49.7 \%, \mathrm{n}=114)$ respondents returned completed questionnaire. From the 114 respondents, $(29.8 \%, \mathrm{n}=34)$ were male and $(70.2 \%, \mathrm{n}=80)$ were female. Majority of the respondent indicated themselves as general dental practitioners (GDP) $(78.1 \%$, $\mathrm{n}=89)$ with $(53.5 \%, \mathrm{n}=61)$ of respondent were practising at the central of Malaysia. Concerning on the year of practices, $(65.8 \%, \mathrm{n}=75)$ had been practising for $1-5$ years, $(23.7 \%, \mathrm{n}=27)$ for $6-20$ years and $(10.5 \%, \mathrm{n}=12)$ had more 20 years of practising experience. The sociodemographic characteristics of study respondents are shown in (Table 1).

Table 1 The respondents' personal and professional background

\begin{tabular}{lr} 
Sociodemographic characteristics & \multicolumn{1}{c}{$\mathbf{n}(\%)$} \\
Mean age & $31.7(9.7)$ \\
$\quad$ Status & \\
GDP & $89(78.1)$ \\
Specialist & $25(21.9)$ \\
Place of employment & \\
$\quad$ Government sector & $90(78.9)$ \\
Private sector & $22(19.3)$ \\
Others & $2(1.8)$ \\
Locations of practice & \\
North territory & $12(10.5)$ \\
South territory & $26(22.8)$ \\
Central & $61(53.5)$ \\
East Coast & $13(11.4)$ \\
Sabah/Sarawak & $2(1.8)$ \\
\hline
\end{tabular}




\section{Preferred Learning Modality}

Most respondents expressed "hands-on workshops" and "hourly lecture" as their preferred learning modality with accredited online CPD were seemed to attract more interest among the respondent. Other preferred learning modalities formats are shown in (Fig. 1).

\section{Number of Educational Activities Attended in 12 Months in 2017}

Data of participation in the various CPD categories were noted in the 12 months in 2017 (Fig. 2). The majority of respondents, either GDP or dental specialist carried out between 1-4 hours of CPD on average per month (Table 2). Further analysis with Fisher's Exact Test revealed no significant association between respondents' status and educational event attended in the year 2017 (Table 3). The CPD attendances were recorded as total days spent by respondent for attending seminar/courses/conferences/ workshop in 2017 (Table 4), with most of them $(41.7 \%, \mathrm{n}=47)$ spent about 5 to

Table 2 CPD hours attended per month in 2017

$$
(n=114)
$$

\begin{tabular}{lr} 
CPD hours (per month) & $\mathbf{n}(\%)$ \\
\hline None & $6(5.3)$ \\
1 to 4 hours & $71(62.3)$ \\
5 to 8 hours & $26(22.8)$ \\
$>8$ hours & $11(9.6)$ \\
\hline
\end{tabular}

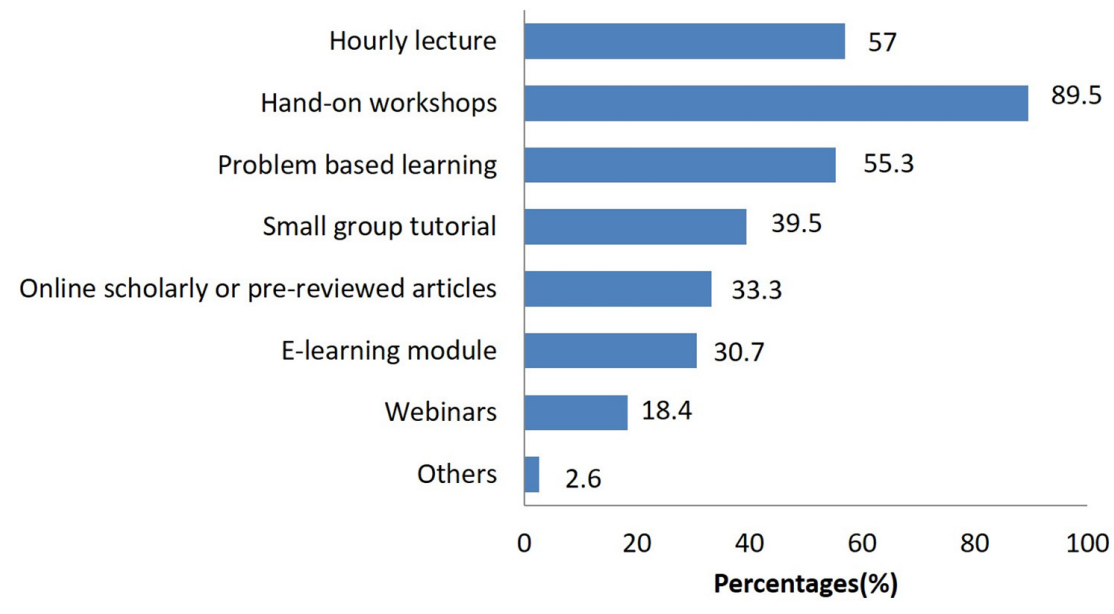

Fig. 1 Preferred learning format for respondents.

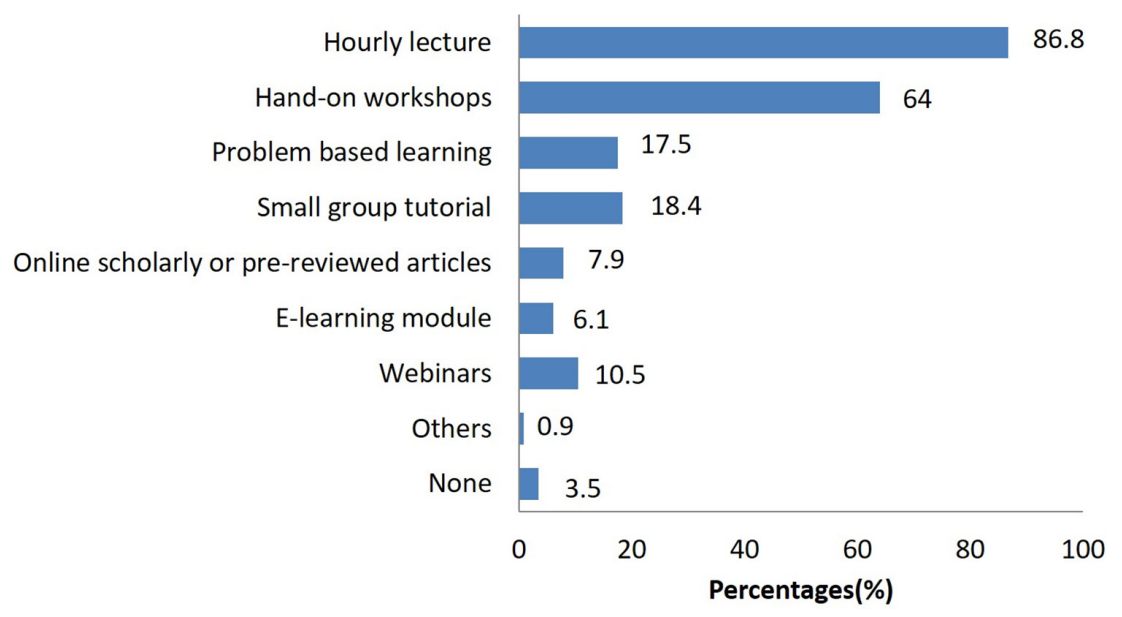

Fig. 2 CPD activities participation among respondent for the past 12 months in 2017. 
Table 3 Association between respondents' status and CPD hours attended $(n=114)$

\begin{tabular}{|c|c|c|c|c|c|c|}
\hline \multirow{2}{*}{ Status } & \multicolumn{4}{|c|}{ Hours per month of CPD, $n(\%)$} & \multirow{2}{*}{$\chi^{2}$ stat } & \multirow{2}{*}{$p$-value } \\
\hline & None & $1-4$ hours & $5-8$ hours & $>8$ hours & & \\
\hline GDP & $3(3.4)$ & $59(66.3)$ & $17(19.1)$ & $10(11.2)$ & 6.864 & 0.058 \\
\hline Specialist & $3(12.0)$ & $12(48.0)$ & $9(36.0)$ & $1(4.0)$ & & \\
\hline
\end{tabular}

*Fisher Exact Test

10 days in total and only $(6.1 \%, \mathrm{n}=7)$ respondents stated that they did not attend any CPD programme in 2017. Analysis using the Fisher's Exact Test indicated that there was a significant association between GDP status and CPD attendance (Table 5).

Table 4 CPD attendance in total spent by respondent attending seminar/courses/ conferences/workshop in $2017(n=114)$

\begin{tabular}{lr} 
CPD attendance & $\mathbf{n}(\%)$ \\
None & $7(6.1)$ \\
1 day & $6(5.3)$ \\
2 to 4 days & $19(16.7)$ \\
5 to 10 days & $47(41.2)$ \\
$>11$ days & $35(30.7)$ \\
\hline
\end{tabular}

\section{Personal Experience in CPD}

Table 6 shows the responses to statements reflecting DPs personal experience of CPD. Nearly all respondents $(92.1 \%, \mathrm{n}=105)$ agreed that it was important to carry out regular CPD, but almost half of DPs $(43.0 \%, \mathrm{n}=49)$ were not routinely recording evidence of activities undertaken in their portfolio. In addition, the majority of respondents $(69.0 \%, \mathrm{n}=79)$ agreed that they received adequate support from employers to carry out regular CPD.

Table 5 Association between respondents' status and CPD attended $(n=114)$

\begin{tabular}{lccccccc}
\multirow{2}{*}{ Status } & \multicolumn{9}{c}{ CPD attendance, $\mathbf{n}(\%)$} & \multirow{2}{*}{$\chi^{\mathbf{2}}$ stat } & $\boldsymbol{p}$-value \\
\cline { 2 - 6 } & None & $\mathbf{1}$ day & $\mathbf{2 - 4}$ days & $\mathbf{5 - 1 0}$ days & $\mathbf{> 1 1}$ days & & \multirow{2}{*}{0.014} \\
GDP & $7(7.9)$ & $5(5.6)$ & $19(21.3)$ & $35(39.3)$ & $23(25.8)$ & 11.446 & \\
Specialist & $0(0.0)$ & $1(4.0)$ & $0(0.0)$ & $12(48.0)$ & $12(48.0)$ & & \\
\hline
\end{tabular}

*Fisher Exact Test

Table 6 DPs' personal experience regarding the CPD $(n=114)$

\begin{tabular}{|c|c|c|c|}
\hline Personal experience & $\begin{array}{l}\text { Agree } \\
\text { n (\%) }\end{array}$ & $\begin{array}{l}\text { Neutral } \\
\text { n (\%) }\end{array}$ & $\begin{array}{l}\text { Disagree } \\
\text { n (\%) }\end{array}$ \\
\hline I feel it is important to carry out regular CPD & $105(92.1)$ & $7(6.1)$ & $2(1.8)$ \\
\hline $\begin{array}{l}\text { I carry out regular CPD activities but do not always } \\
\text { record evidence in my portfolio }\end{array}$ & $49(43.0)$ & $29(25.4)$ & $36(31.6)$ \\
\hline $\begin{array}{l}\text { I should face disciplinary action if I fail to carry out } \\
\text { and record regular CPD activities }\end{array}$ & $24(21.0)$ & $42(36.8)$ & $48(42.1)$ \\
\hline $\begin{array}{l}\text { I feel I have plenty of time to carry out CPD activities } \\
\text { during my paid employment time }\end{array}$ & $49(43.0)$ & $33(28.9)$ & $32(28.1)$ \\
\hline $\begin{array}{l}\text { My employer provides adequate support for me to } \\
\text { carry out CPD activities }\end{array}$ & $79(69.3)$ & $23(20.2)$ & $12(10.6)$ \\
\hline $\begin{array}{l}\text { I find it easy to identify appropriate CPD activities } \\
\text { which will aid my professional development }\end{array}$ & $76(66.7)$ & $27(23.7)$ & $11(9.6)$ \\
\hline
\end{tabular}




\section{Perceived Barriers Preventing Engagement in CPD Activities}

Fig. 3 shows the perceived barriers that prevent engagement in CPD activities among DPs. Majority of the DPs stated that lack of time and lack of financial resources to be the main obstacles in attending the CPD activities. Topic related to their interest and CPD point were the main reasons for DPs in choosing the CPD programme. Fig. 4 shows the factors that were influencing the respondents in choosing the CPD programme.

\section{DISCUSSION}

\section{Profile Respondent and DP Personal Experience on CPD Programme}

The present study covered the investigation of Malaysian DPs' personal experience on CPD and perceived barrier in attending CPD programme. Following new regulation on mandatory CPD, which had been introduced in Malaysia in 2018 (Dental Act, 2018), our study found that most of Malaysian DPs considered compulsory CPD to be beneficial and valuable to them as

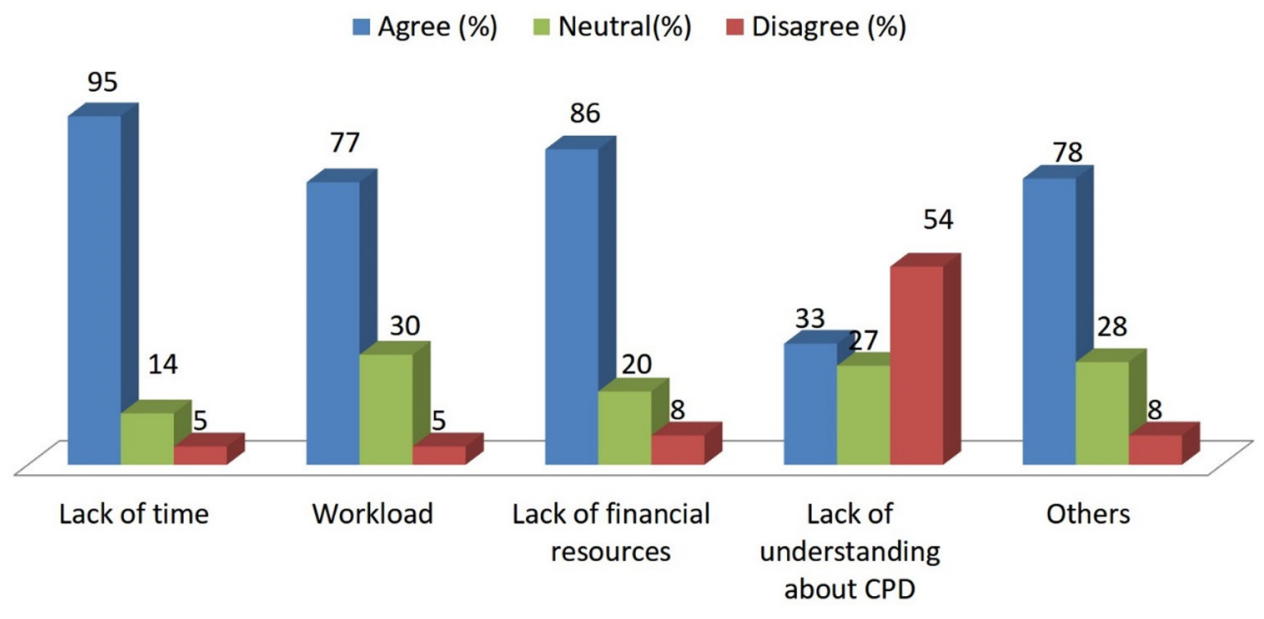

Fig. 3 Perceived barriers preventing engagement in CPD activities.

\section{Percentages (\%)}

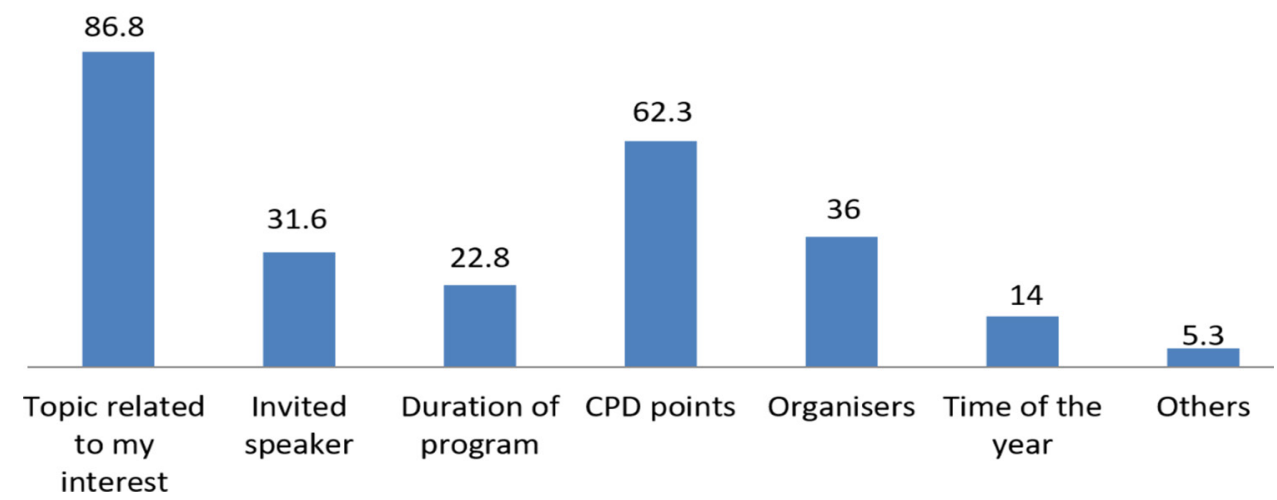

Fig. 4 Factors that influenced the respondents in choosing the CPD programme. 
professionals, as well as to their organisation and patients even before the compulsory implementation. While more than half of respondent agreed that their employers provide adequate support for them to carry out CPD activities, contradict statements were noted as majority of them stated that lack of time to be the main barrier in attending the CPD programme. Surprisingly, our study found that few DPs favoured compulsory requirement with penalties to be imposed if they failed to carry out and record regular CPD activities which are similar to a previous study (Sturrock and Lennie, 2009).

Our study found that most of the respondents work around the central region of Malaysia, which is close to the University Teknologi MARA as the CPD provider. In Malaysia, Ministry of Health, Ministry of Higher Education, Ministry of Defence and Malaysian Dental Association (MDA) were among the main CPD providers other than Professional Bodies such as the World Health Organisation (WHO) or Federation Dentaire Internationale (MDC, 2018; MDA, 2019). Most of the CPD providers preferred to organise big CPD courses around the central region of Malaysia as it was easier to attract more participants not only from Malaysia but around the neighbouring regions. Nevertheless, every year MDA has taken an initiative to arrange and coordinate small CPD courses according to the region, including the Northern Zone, Southern Zone and Eastern Zone (MDA, 2019). This is to cater the DPs who are working around the area where the geographical location makes access to CPD course difficult for some of them.

\section{Preferred Learning Modality}

The majority of the respondents preferred the traditionally associated learning activities such as formal lecture and hands-on workshops rather than those self-directed learning activities. Although according to the previous study, conventional lectures have shown to have less impact (Davis et al. 1999), the cost-effective nature in delivering information in large groups was undeniable. With the advanced technology, most of the lectures nowadays are more interactive and allow interaction between speaker and participant even in between the lectures. Although our survey reported low interest in accredited online CPD, many studies reported that e-learning was well-accepted as a method of distance learning (Francis et al., 2000; Eaton and Hammick, 2003; Yilmaz, 2017). However, as compared to hands-on workshop, it is well-known that e-learning may have limited potential for teaching clinical skills that may be a major drawback that limits the participation among our respondents (Cantoni et al., 2004; Yilmaz, 2017).

\section{Attendance at CPD Courses}

Most of the respondents participated actively in CPD courses with both GDP and specialists spending more than five days in attending CPD course in the year 2017. Of note, the present survey was conducted a year before mandatory enforcement of Dental Act 2018 that linked recorded CPD points prior to the renewal of APC and TPC (Dental Act, 2018; MDC, 2018). We found a positive engagement on CPD activities which indicated progressive support towards the programme. This was in accordance to a previous study in Australia, which also documented increased participation and mean hours of attendance in CPD activities among Victorian dentists before the introduction of mandatory CPD (Hopcraft et al., 2010).

\section{Perceived Barriers to Attend CPD}

Although respondents recognised the importance of CPD, $71.0 \%$ of them indicated funding as one of the main obstacles to attend the CPD programmes besides the lack of time and the substantial workload. As compared to private dental practitioners, DPs working under the Ministry of Health and government universities in Malaysia received some financial support in terms of the funding 
scheme for DPs to attend one or two CPD courses per year. However, this may vary based on the availability of budget allocation each year. Since the mandatory CPD had been implemented in 2018, it is wise to re-examine the CPD funding structure to allow all DPs to participate actively in CPD courses. Recommendations can be suggested to DPs who experiences the barriers of time and place to use other forms of CPD activities such as distance learning which could be carried out anywhere at their own convenient time. The use of audio-based material, video-based material, computer-based material which include video-conferencing and streaming, internet forums and chat rooms is the new approach of learning methods to deliver learning materials to the DPs (Eaton and Hammick, 2003; Yilmaz, 2017). Besides the above issues, other challenges reported from the previous study included work and home commitment, location of the course, the internal issue with the management, lack of understanding of CPD and other domestic commitment (Leggate and Russell, 2002; Barnes et al., 2012; Summers, 2015)

Moreover, our study found that topics related to respondent's interest and course content could influence the DPs in choosing the CPD programmes besides the invited speaker which corresponds to previous studies (Leggate and Russell, 2002; Barnes et al., 2012). However, the DPs' preferences for CPD on a certain topic might not reflect the real educational needs among them but rather their self-perceived needs. Nevertheless, our findings would have a positive input for the CPD providers for planning future CPD programmes. Additionally, the duration of the programme, CPD points, organisers and time of the year could be the factors that might influence the DPs in choosing the CPD programmes.

\section{Limitation of Study}

Data from this survey could provide valuable insights on the personal experience of DPs towards the CPD programmes as well as barriers in attending the CPD course, albeit limited. Although minimum sample required after sample size calculation indicated as 143 , the final respondents of our study are 114 samples. Lower number was achieved as the respondents required to answer at least $70 \%$ of the questions to be included in the study. Unsatisfactory response rate or incomplete answer may suggest the presence of non-response bias, where those who chose not to answer may have different view from those who answered. This however remains as assumption as it is beyond our control. Besides, the total of 114 respondents only represents $2.9 \%$ of all current Malaysian DPs, which could create a bias to the overall finding as it is only restricted to a very small population of DPs in Malaysia. Thus, significant views of other DPs who did not respond were not captured by this specific research methodology. As lack of interest towards research material has been previously linked with low response rate (Cottrell et al., 2015), the validity of the current findings might be compromised if non-respondents have negative views of the CPD concept. Thus, for future research, it could be suggested that an online survey to be introduced for administration of questionnaire and to include a larger sample size with more systematic sampling technique, in order to have a true representation of Malaysian DPs. Despite the limitation, our study managed to reflect the national representation of male: female ratio and include all DPs that worked in the different sectors as well as covered most parts of Malaysia. The current findings could provide valuable insights to the CPD providers to ensure an effective CPD could be delivered following the implementation of mandatory CPD. Furthermore, further research might be required to assess the impact of mandatory CPD attendance on improved clinical outcomes for patients.

\section{CONCLUSION}

It is important to understand the perceived needs and barriers to CPD among DPs, as 
mandatory CPD for registration or licensure had been implemented following the Dental Act 2018. The concept of CPD is clearly embedded within the profession although the present survey was conducted a year before mandatory reinforcement of Dental Act 2018. It is essential to ensure that the development of effective educational and training programmes can be delivered in the future to support our DPs towards successful revalidation.

\section{ACKNOWLEDGEMENTS}

The authors wish to thank Assoc. Prof. Dr Mas Suryalis Ahmad for her assistance with the content validation of the questionnaire. The authors also wish to thank Miss Nur Elida Shahira Khairul Anwar and Miss Nur Fara Izani Muhammad Nor Ikhwan Tan for assisting in data collection for this study and to all dental practitioners who participate in this study.

\section{CONFLICT OF INTEREST}

The authors state that they have no conflicts of interest with respect to their authorship or the publication of this article.

\section{REFERENCES}

Barnes E, Bullock AD, Bailey SER, Cowpe JG, Karaharju-Suvanto T (2012). A review of continuing professional development for dentists in Europe. Eur f Dent Educ, 16(3): 166-178. https://doi.org/10.1111/j.1600 $-0579.2012 .00737 . x$

Cantoni V, Cellario M, Porta M (2004). Perspectives and challenges in e-learning: Towards natural interaction paradigms. f Visual Lang Comput, 15(5): 333-345. https://doi.org/10.1016/j.jvlc.2003.10.002
Cottrell E, Roddy E, Rathod T, Thomas E, Porcheret M, Foster NE (2015). Maximising response from GPs to questionnaire surveys: Do length or incentives make a difference? $B M C \mathrm{Med}$ Res Methodol, 15:3. https://doi.org/10.1186/ 1471-2288-15-3

Davis D, O'Brien MA, Freemantle N, Wolf FM, Mazmanian P, Taylor-Vaisey A (1999). Impact of formal continuing medical education: Do conferences, workshops, rounds, and other traditional continuing education activities change physician behavior or health care outcomes? $\mathcal{F} A M A$, 282(9): 867-874. https://doi.org/10.1001/ jama.282.9.867

Dental Act 2018 (Act 804) (2018). Retrieved 6 January 2020, from http://www. federalgazette.agc.gov.my/outputaktap/ aktaBI_20180626_AktaPergigianBI.pdf

Eaton K, Hammick M (2003). Distance learning materials for dentists-a user's guide to quality. $\mathrm{Br}$ Dent f, 194(5): 253-256. https://doi.org/10.1038/sj.bdj.4809926

Francis B, Mauriello SM, Phillips C, Englebardt S, Grayden SK (2000). Assessment of online continuing dental education in North Carolina. I Contin Educ Health Prof, 20(2): 76-84. https://doi.org/10.1002/chp .1340200203

Hopcraft MS, Manton DJ, Chong PL, Ko G, Ong PYS, Sribalachandran S et al. (2010). Participation in continuing professional development by dental practitioners in Victoria, Australia in 2007. Eur $\mathcal{F}$ Dent Educ, 14(4): 227-234. https://doi.org/10 $.1111 / \mathrm{j} .1600-0579.2010 .00615 . x$

Ikenwilo D, Skåtun D (2014). Perceived need and barriers to continuing professional development among doctors. Health Policy, 117(2): 195-202. https://doi.org/10.1016/ j.healthpol.2014.04.006 
Leggate M, Russell E (2002). Attitudes and trends of primary care dentists to continuing professional development: A report from the Scottish dental practitioners survey 2000. Br Dent $\mathcal{F}$, 193(8): 465-469. https://doi.org/10.1038/sj .bdj. 4801598

Malaysian Dental Association (MDA) (2019). MDA News, Oct-Dec 2019. Retrieved 6 January 2020, from https://www.mda.org .my/newsletter/2019/2019-10-12/MDA-Oct -Dec\%202019.pdf

Malaysian Dental Council (MDC) (2018). MDC Bulletin, Vol. 14, No. 2. Retrieved 6 January 2020, from http://mdc.moh.gov .my/uploads/juldis2018.pdf

Malaysian Dental Council (MDC) (2019). MDC Bulletin, Vol. 15, No. 2. Retrieved 6 January 2020, from http://mdc.moh.gov .my/uploads/juldis2019.pdf
Sturrock JBE, Lennie SC (2009). Compulsory continuing professional development: A questionnaire-based survey of the UK dietetic profession. F Hum Nutr Diet, 22(1): 12-20. https://doi.org/10.1111/j.1365277X.2008.00935.x

Summers A (2015). Continuing professional development in Australia: Barriers and support. I Contin Educ Nurs, 46(8): 337339. https://doi.org/10.3928/0022012420150721-11

Yilmaz R (2017). Exploring the role of e-learning readiness on student satisfaction and motivation in flipped classroom. Comput Hum Behav, 70: 251-260. https://doi.org/10 $.1016 /$ j.chb.2016.12.085 